\title{
RELATIVIZANDO O SADOMASOQUISMO PARA UMA NOVA ABORDAGEM SEXOLÓGICA
}

\author{
Fernando Luiz Cardoso ${ }^{1}$ \\ REVIEWING THE CONCEPT OF SADOMASOCHISM FOR A NEW SEXOLOGICAL \\ $A P P R O A C H$
}

\begin{abstract}
Resumo: Este artigo discute um assunto extremamente polêmico na cultura brasileira e ainda recente na academia e no meio clínico - o sadomasoquismo. Ao discutir as práticas e os significados do mundo sadomasoquista em um sentido introdutório, conceitual, crítico e científico, invariavelmente temos de tocar nas já tão discutidas relações de gênero e poder. Este artigo traz algumas contribuições sobre como as relações dicotômicas como masculino e feminino, dominante e dominado tornam-se um potente combustível nas relações eróticas consideradas marginais, independentemente da orientação sexual de seus participantes. Tem como maior contribuição relativizar o conceito de normalidade e de doença no meio clínico e acadêmico.
\end{abstract}

Palavras-chave: Sadomasoquismo; sexualidade; gênero; corporeidade.

\begin{abstract}
This article discusses an extremely controversial and still recent subject in the Brazilian culture and in the clinic and academic environments - the sado-masochism. When discussing the practices and the world sado-masochist's meanings in an introductory, conceptual, critical and scientifically sense, we have invariably to talk on genders roles and power relationships. This article brings some contributions on, as the relationships between masculine and feminine, dominant and dominated become a potent fuel in these said erotic and marginal relationships, independent of ones participants' sexual orientation. Its larger contribution is to question the concept of normality and of disease in the clinic and academic environment
\end{abstract}

Keywords: Sado-masochism; sexuality; gender; body awareness

\footnotetext{
${ }^{1}$ Professor Adjunto junto ao Programa de Mestrado em Ciência do Movimento Humano da Universidade do Estado de Santa Catarina - UDESC. Mestre em Antropologia Social pela UFSC, Mestre em Saúde Pública pelo IASHS (EUA) e Doutor em Sexualidade Humana pelo IASHS (EUA). e-mail: d2flc@udesc.br
} 


\section{Introdução}

Pode-se dizer que, depois da transexualidade e da homossexualidade, o sadomasoquismo é um dos últimos grandes tabus da sexualidade humana ou, até mesmo, um grande ícone do que seja considerado desviante e repugnante em termos de sexualidade humana. Quando se aborda esse fenômeno, inclusive nos círculos acadêmicos, percebe-se que o assunto está carregado de um simbolismo bárbaro, hediondo, irracional e violento. No entanto, a literatura acadêmica atual e o convívio com as comunidades e organizações sadomasoquistas expressam uma realidade muito diferente.

"Sadomasoquismo" (ou S \& M, tal como o denominam os norte-americanos) é um termo combinado que tem sido tradicionalmente usado para designar o dar e receber dor com objetivo de gratificações eróticas. Existem dois pontos estratégicos para se entender esse fenômeno de um ponto de vista antropológico ou sociológico: ele ocorre em um contexto "clandestino" e é viabilizado através de uma organização social mínima.

Durante muito tempo, as práticas sexuais sadomasoquistas foram tratadas como um comportamento patológico. Freud (1983) descreveu o masoquismo como uma perversão, enquanto Stekel (1953) relacionou o masoquismo ao canibalismo, à criminalidade, ao vampirismo, ao assassinato em massa, à necrofilia, à epilepsia, à pederastia e a demais práticas dessa ordem. Reik (1941), por sua vez, disse que todos os neuróticos são masoquistas. Além disso, de acordo com o Manual Diagnóstico e Estatístico dos Transtornos Mentais (DMS-IV, 1994) da Sociedade Norte-Americana de Psiquiatria, o sadomasoquismo é considerado um transtorno psicossexual. Isso significa que qualquer pessoa que se engaje regularmente em práticas sexuais sadomasoquistas é considerada, por definição, mentalmente doente.

No entanto, estudos mais recentes mostram-nos um cenário completamente diferente. Observações empíricas têm descrito os praticantes do sadomasoquismo como pessoas extremamente típicas, ao menos no que tange ao cotidiano de suas vidas. Scott (1983) descreveu a participação em práticas sadomasoquistas de mulheres mais 
educadas e com salários e ocupações profissionais acima da média da população norteamericana. Spengler (1977), que estudou alemães sadomasoquistas, descreveu-os como sendo representantes da classe alta e de um grupo de pessoas muito bem-sucedidas na vida. Janus, Bess e Saltus (1977), que estudaram o perfil de homens poderosos, ficaram surpresos com a grande quantidade de atividades sexuais masoquistas entre políticos de sucesso e outras figuras de influência. Hayden (2003) psicoterapeuta especializada em fetiches e dependentes de sexo, também tem uma visão bastante positiva dos sadomasoquistas. De acordo com a autora, os seus pacientes não parecem imaturos ou inferiores e, muito pelo contrário, têm demonstrado que são pessoas bem-sucedidas, segundo os modelos vigentes para a vida profissional, sexual, emocional e cultural nos Estados Unidos, em suas relações afetivas com parceiros ou amigos. Além disso, apresentam um "bom caráter", bem como um forte senso de ética e de responsabilidade pessoal.

Assim como muitos outros comportamentos humanos, o sadomasoquismo é profundamente influenciado, estruturado e significado a partir das relações típicas de gênero e poder vigentes em nossa sociedade. Se nas relações de gênero trabalhamos com categorias binominais como macho-fêmea, homem-mulher, masculino-feminino, no sadomasoquismo empregamos uma dualidade analítica similar, como sádico-masoquista, dominante-dominado, mestre-escravo, etc.

Este artigo tem como principal objetivo apresentar e desconstruir essa percepção equivocada e moralista das práticas sadomasoquistas, além de discutir as relações de gênero e poder intrínsecas a essas atividades, como o atual fenômeno da organização política sadomasoquista que busca maior visibilidade e aceitação social nos Estados Unidos. 


\section{A Organização Civil Sadomasoquista}

Todos os anos, aproximadamente 300 mil pessoas interessadas em roupas e apetrechos de couro, de látex e outros fetiches comparecem à maior festa pública sadomasoquista do mundo em São Francisco, na Califórnia (EUA). A Folson Street Fair, que neste ano realizará a sua vigésima versão, é considerada a maior celebração das desviantes formas de se amar, esboçando uma forte organização política.

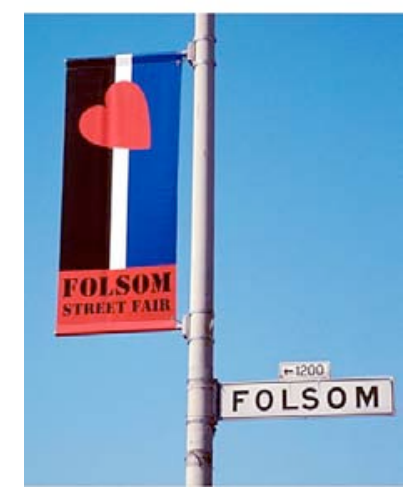

Foto 01: Bandeira do movimento S\&M nos

Estados Unidos

(Cardoso, 2001)

Essa festa surgiu com o intuito não só de confraternizar os adeptos do sadomasoquismo e de outras minorias sexuais, como também de resgatar a dignidade de uma vizinhança estigmatizada pelos submundos do sexo, da prostituição, do álcool, das drogas, da pobreza e da marginalização. Para os seus praticantes, "sair do armário" como seres "anormais" e "estranhos" significa denunciar e expor as atitudes hipócritas da nossa sociedade, que privilegia a liberdade e a democracia

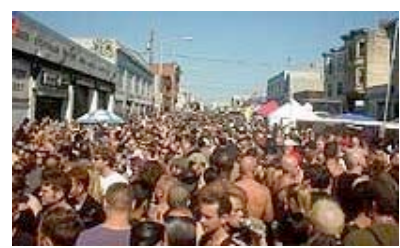


formal, mas nega a existência das minorias constituintes dessa mesma sociedade. Não é à toa que a "Folsom Fair" tem pleno apoio da comunidade gay em São Francisco.

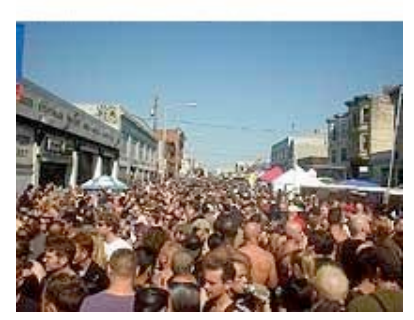

Foto 02: Vista parcial da

Folsom Fair Street/ 2001

(Cardoso, 2001)

A festa acontece em um único dia no final de setembro, em pleno Indian Summer (o verdadeiro verão de São Francisco), das $9 \mathrm{~h}$ às $17 \mathrm{~h}$, na rua Folsom, situada entre a sétima e a décima segunda rua no coração da cidade. A comissão organizadora, que conta com o apoio de muitos voluntários, restringe o acesso à festa com o objetivo de arrecadar doações em dinheiro dos seus visitantes e participantes. Além das doações individuais voluntárias, todo e qualquer lucro oriundo da venda de comida e bebida é revertido para instituições beneficentes que apóiam programas de ajuda e pesquisa em AIDS, por exemplo. A festa de 2002 arrecadou US \$291.000 dólares.

Além de muita música, bebida e comida, o visitante tem a oportunidade única de se deparar com cenas fortes, pesadas, bizarras e por vezes engraçadas no tocante à sensualidade e à sexualidade humanas. Demonstrações públicas de espancamentos com a utilização de inúmeros e diversos apetrechos, surras com sonoros chicotes, exposição de variadas técnicas de bandagem e imobilização e demonstrações públicas de sexo solitário, em casais ou em grupos, são algumas das atrações que mais chamam a atenção dessa festa inusitada. 


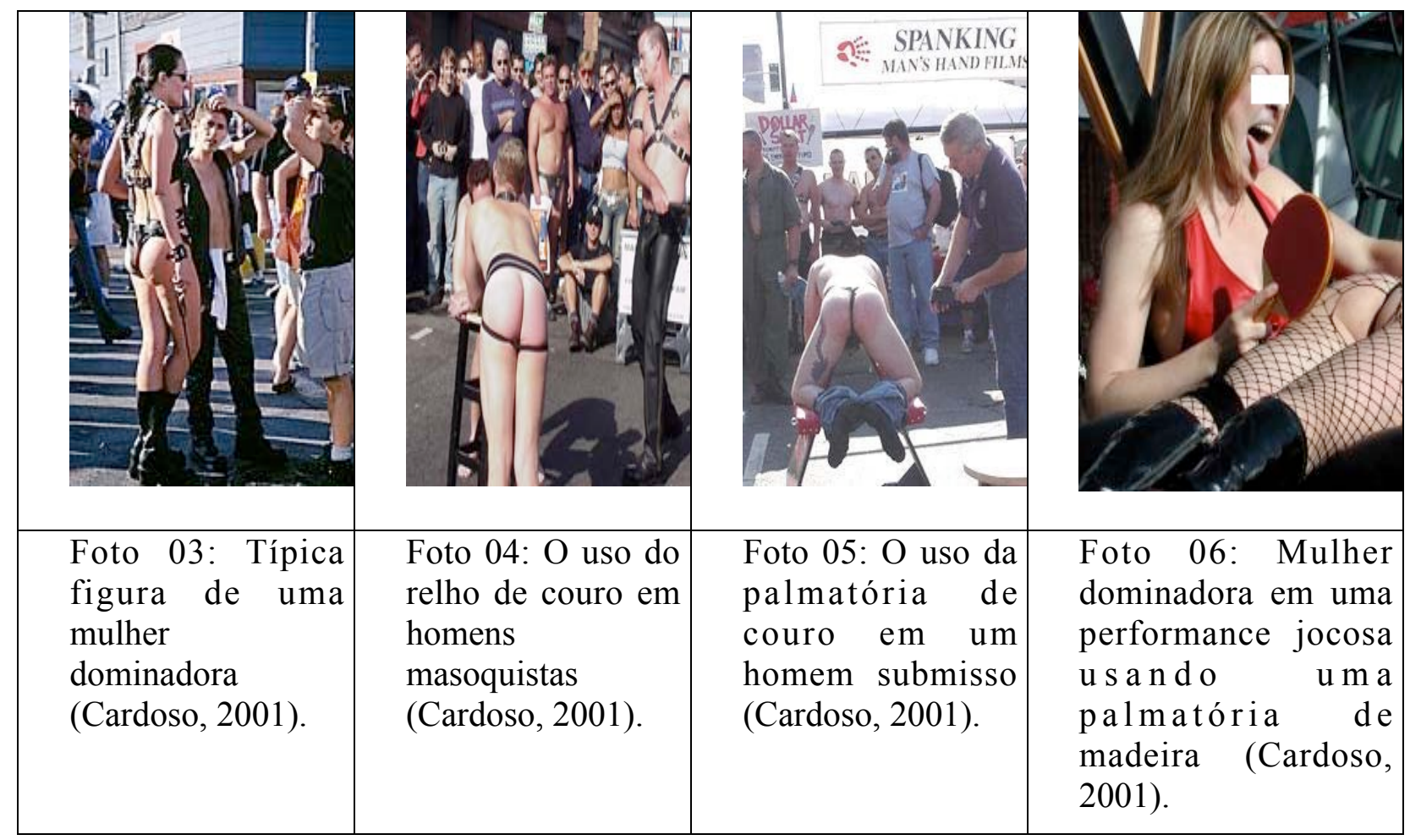

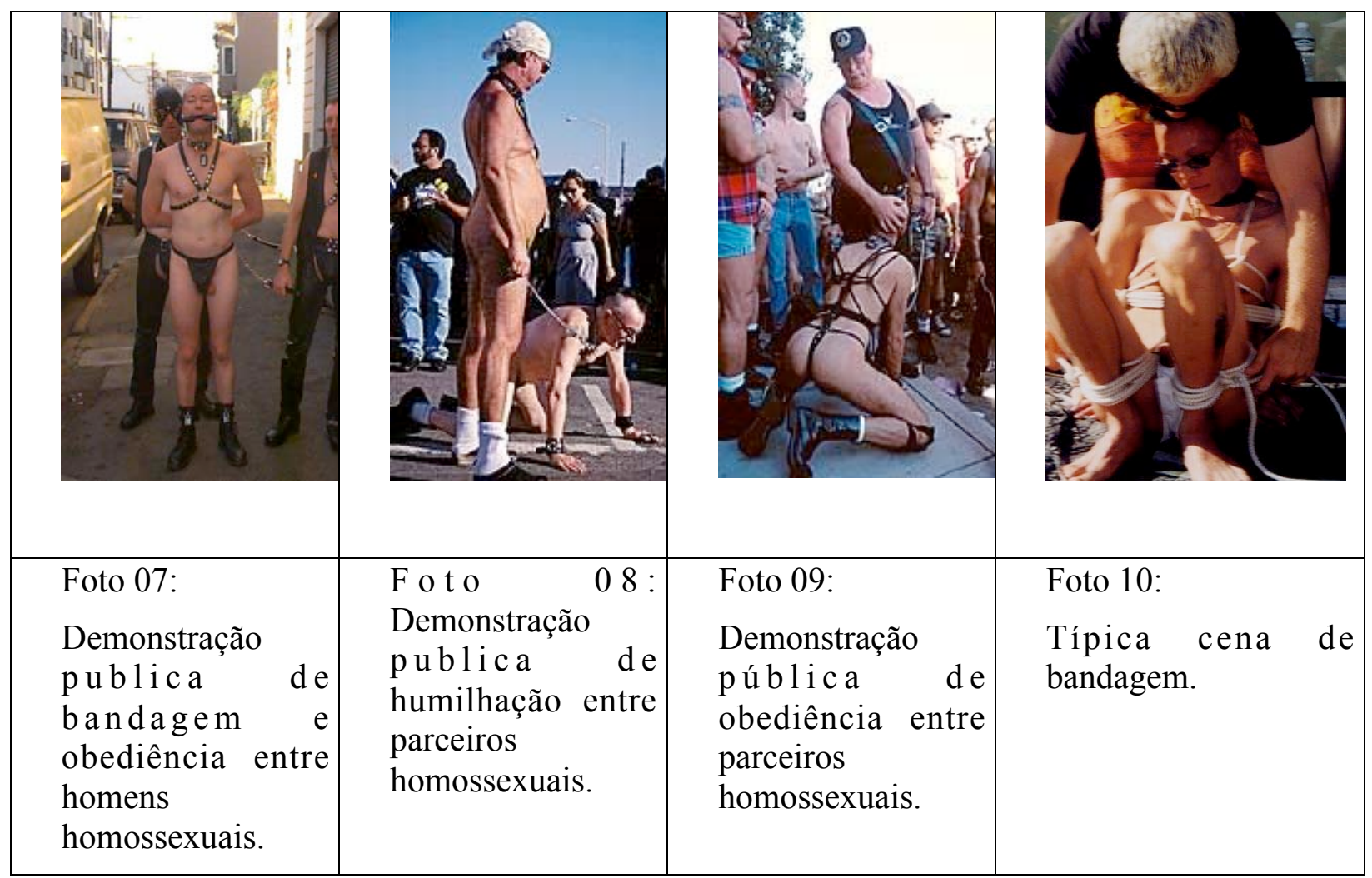

(Fotos retiradas de sites abertos na internet) 


\section{Contextualização Histórica}

Sadismo e masoquismo foram inicialmente introduzidos com certa consistência científica pelo psicanalista Richard von Krafft-Ebing. Em sua obra "Psychopathia Sexualis", publicada em 1885, Krafft-Ebing definiu sadismo como uma experiência sensível prazerosa do sexo produzido a partir de atos de crueldade e submissão de outros a punições corporais, podendo ser humanos ou animais. Ele acrescenta que esse sentimento consiste em um desejo "natural" de humilhar, torturar, machucar ou até mesmo destruir o outro com o intuito de criar prazer sexual. O termo sadismo deriva-se de Marquês de Sade, um nobre escritor francês que viveu entre o final de século XVIII e o início do século XIX. Muitas das histórias e novelas de Sade incluem paixão, assim como crueldade, dor e humilhação como forma de prazer sexual. Krafft-Ebing derivou o termo masoquismo do nome de Leopold von Sacher-Masoch, cujas novelas, como "Vênus in Furs", refletiam sua pessoal preocupação erótica com a dor, a humilhação e a submissão (WEINBERG \& KAMEL, 1983).

Literatura e escritos que abordam o masoquismo surgiram inicialmente no século XVII na Europa (TAYLOR, 1970; BULLOUGH, 1976). Segundo historiadores da sexualidade humana, o fenômeno masoquismo não é evidenciado até por volta do século XVIII, quando então sua prática torna-se notória no velho continente. Nas evidências históricas oriundas do século XVIII, existem inúmeras referências a prostitutas especializadas em flagelação (BENJAMIN \& MASTERS, 1965; TANNAHILL, 1980). No século XIX, muitos dos grandes bordéis já contavam com prostitutas especialistas e nas grandes cidades existiam bordéis voltados somente à prática da flagelação (TANNAHILL, 1980).

\section{Contextualização Teórica}

A posição teórica prevalente desde Freud tem sido a de que o masoquismo é uma derivação do sadismo. Assim, muitos teóricos têm assumido essa forte ligação entre sadismo e masoquismo, enfatizando que o sadismo por ser, a princípio, o comportamento mais importante e fundamental. Entretanto, várias evidências 
contradizem tal percepção, por exemplo, os masoquistas são aparentemente em um número muito maior do que os sádicos em relação aos heterossexuais (JANUS, BESS \& SALTUS, 1977; FRIDAY, 1980; SAMOIS, 1982; SCOTT, 1983), fato que se repete entre os homossexuais (KAMEL, 1983; LEE, 1983; SCOTT, 1983) e entre as lésbicas (CALIFIA, 1983). Em suma, o peso das evidências empíricas não sustenta a percepção teórica inicial de que o masoquismo seja uma derivação do sadismo, mas sim o contrário, isto é, o masoquismo seria anterior ao sadismo e mais fundamental, embora sejam necessários mais estudos explicativos a fim de melhor situar essa possível relação causal, se é que existe.

Geralmente, os críticos do sadomasoquismo, como algumas feministas no passado, baseavam-se a sua visão sobre tais práticas como sendo atividades que endossam a opressão e a violência, incluindo as brutalidades nazistas, os genocídios, as torturas medievais, o estupro, etc. O problema é que essas críticas tornam-se infundadas, na medida em que comprovamos que o masoquismo é mais recorrente entre brancos do que entre negros, entre homens do que entre mulheres, entre as classes mais educadas do que entre as classes populares (SPENGLER, 1977; SYMANSKI, 1981; SCOTT, 1983).

John Money (1998) classificou o comportamento sexual humano como normofílico e parafílico. Por normofília, Money entende o mapa amoroso típico da maioria numérica da população que consegue articular amor e sexo em um mesmo objeto de prazer, ou seja, em uma mesma pessoa. O mapa amoroso normofílico também apresenta diferentes níveis dessa articulação entre amor e sexo. Algumas pessoas não conseguem separar esses dois aspectos e praticam sexo apenas quando amam, ao passo que outras conseguem distinguir e viver somente o sexo em algumas situações.

Por parafília, Money compreende o mapa amoroso de uma minoria da população que tem dificuldades de conciliar, mesmo que eventualmente, amor e sexo. Assim, o parafílico desenvolveria uma sexualidade considerada por muitos como exótica ou "desviante", pois inclui outros aspectos incomuns em sua vida sexual típica. Enfim, segundo Money, o sadomasoquismo seria um tipo de parafilia na qual não se consegue, ainda que se tente, reunir em uma única pessoa amor e desejo sexual. 
No entanto, as pesquisas aqui referenciadas (BAUMEISTER, 1988; HAYDEN, 2003) evidenciam que os sadomasoquistas não têm nada de diferente em seus mapas amorosos em termos de amor e sexo; eles apenas adicionam algo mais. Casam-se ou estabelecem relações amorosas duradouras, além de ter amigos e conhecidos que compartilham os seus interesses.

Muitas são as tentativas de generalizar o comportamento masoquista como um comportamento autodestrutivo (STEKEL, 1953; LEWIN, 1980; SHAINESS, 1984; FRANKLIN, 1987) pelo fato de os masoquistas procurarem machucar-se física e psicologicamente. Stricto sensu, se os masoquistas assumem que procuram a dor, e a dor geralmente é tida como um alarme biológico contra possíveis danos à saúde e à vida humana, tem-se a impressão de que eles se autoflagelam. O que se percebe nas práticas sadomasoquistas é que os masoquistas persistentemente - e realmente - procuram a dor, porém evitam cuidadosamente se machucar nessas atividades. Este é um de seus principais lemas: a promoção gradual da dor deve ser acompanhada de cuidados no sentido de evitar qualquer tipo de ferimento a quem se submete à arte do seu mestre. Os sadomasoquistas transgridem os limites da violência simbólica ritualizando em termos de comportamento os estereótipos das relações de poder com o objetivo de eliciar o erótico para quem participa.

Portanto, a questão masoquista pela procura da dor deve ser entendida a partir de outros motivos que apenas o simples desejo de se ferir. Segundo Baumeister (1988), o masoquismo representa uma tentativa sistemática de erradicar temporariamente importantes estruturas perceptivas do ego, um agente ativo que faz escolhas e toma iniciativa. Assim, nas sessões de sadomasoquismo, a parte do indivíduo responsável por avaliações interativas com o meio ficaria temporariamente eliminada, como se ele "tirasse férias" de si mesmo.

Por que, então, as pessoas desejariam escapar de si mesmas ou perder a consciência temporária do que são? Em muitas situações cotidianas, diante de experiências frustrantes, humilhantes ou estressantes, manter um contato íntimo com o ego pode tornar-se incômodo e desconfortável, o que estimularia uma aversão do próprio indivíduo a continuar em constante consciência de si mesmo. Esse desejo intrínseco tem 
sido relacionado na literatura ao uso do álcool (HULL \&YOUNG, 1983, 1981; HULL, YOUNG \& JOURILES, 1986) e do cigarro (LIEBLING, SEILER \& SHAVER, 1974; WICKLUND, 1975). Seria plausível também que as fugas de consciência do seu próprio ego estivesse relacionadas a outras atividades recreativas, como praticar esportes, assistir a filmes e ingerir drogas.

Essa teoria poderia explicar por que o masoquismo é tão popular entre os poderosos homens com forte auto-estima estudados por Janus e colaboradores (1977). Níveis elevados de auto-estima e responsabilidade produzem egos mais complexos e elaborados, o que, por outro lado, também produz egos mais ansiosos por fugas de si mesmos. Essa hipótese poderia ser tomada como um bom suporte para uma idéia menos monolítica de poder anteriormente difundida por Foucault(1985).

De acordo com Baumeister (1988), existem duas formas básicas de se escapar da percepção normal e familiar de si mesmo: centralizar a autopercepção de si no seu próprio corpo como uma forma mais imediata e concreta de experiência, ou criar, fantasiar uma identidade que seria totalmente diferente da sua, principalmente negando aqueles traços pessoais que impedem uma razoável administração de conflitos internos tão incômodos. Resumindo, a dor masoquista pode funcionar como uma técnica para remover o alto nível de percepção de si, à medida que promove um baixo nível de autoconsciência de si mesmo enquanto objeto. A dor diminui o nível de autopercepção de si de um nível mais simbólico para um mais concreto - o corpo físico.

\section{Contextualização Clínica}

Tem-se tornado praticamente um dogma para o pensamento psicanalítico que o masoquismo seja uma condição sexual na qual a punição é um dos requisitos antes de se atingir a satisfação. Freud interpretou esse fenômeno como o resultado de um sentimento inconsciente de culpa que exige punição por parte da autoridade paterna ou materna. Em 1919, encontrou a gênese e um ponto de referência para o masoquismo dentro da sua ideia do complexo de Édipo. Assim, para Freud, o masoquismo surgiria na sexualidade infantil quando o desejo incestuoso pelo pai ou pela mãe deve ser reprimido. A culpa faz-se presente nesse ponto em conexão com o desejo incestuoso. As figuras do pai e da 
mãe transformam-se em um atributo da punição, em vez do amor, e surge daí o desejo de ser batido, espancado, maltratado, etc. A fantasia de ser espancado transforma-se em um ponto de encontro entre o sentimento de culpa e o desejo amoroso; independentemente de sentir dor ou não, a punição desejada pelo masoquista é desfrutada por si só. A punição e a satisfação produzem prazer, assim como a humilhação. Ao referir-se ao masoquismo como uma perversão, Freud situou-o para sempre no campo da aberração (FREUD, 1953).

Segundo os relatórios clínicos de Hayden (2003), os submissivos geralmente relatam um sentimento de fuga, liberdade e expansão de si mesmos nas cenas sadomasoquistas, em que as próprias defesas internas são destruídas. Eles relatam uma experiência de completa vulnerabilidade. A autora acredita que essa tensão é um desejo por algo no ambiente que torne possível uma rendição do ego em um sentido proveitoso de desmascarar o seu falso self.

O falso self é uma idéia desenvolvida por Freud, a qual postula que a maioria dos pais requer que suas crianças comportem-se adequadamente para receber o seu amor.

Como para a criança o amor dos pais é uma questão de sobrevivência, ela se molda de acordo com as expectativas dos seus pais. O falso self é geralmente um vigia do self. A exposição a uma situação de submissão e humilhação às vezes permite que anos de esforços empenhados na construção dessa barreira sejam rompidos, o que estimularia o desejo do nascimento ou o surgimento do seu verdadeiro self. No fundo, surge o desejo de desistir ou de abandonar esse falso self como parte do desejo maior de se conhecer e ser reconhecido. A perspectiva de rendição do falso self pode ser acompanhada por um sentimento de medo, alívio e êxtase. A intensidade do masoquismo seria uma testemunha viva da urgência de algumas partes escondidas da personalidade que está exigindo ser libertada. A rendição seria nada mais do que a dissolução controlada das fronteiras do self (HAYDEN, 2003).

As técnicas psicoterapêuticas têm sido dirigidas para construir egos mais fortes, vigilantes e racionais. Esses valores do ego são certamente muito importantes para o equilíbrio psicológico do indivíduo, mas ao mesmo tempo contribuem para desativar muitos sentimentos após anos de terapia. Assim, construir egos fortes é apenas uma 
parte da tarefa, pois nesse processo geralmente negamos outras partes cruciais do ser humano. Nesse sentido, Jung (1964) nos traz algumas contribuições para melhor entendermos o masoquismo. Podemos imaginá-lo como uma construção que Jung chama de "sombra" - a porção escura do ser, a sua maior parte imersa no inconsciente. A sombra seria um túnel, um canal ou um ducto através do qual seriam atingidas as dimensões mais profundas da psique. Ao atravessar esse túnel, ou romper as defesas do self, o ser sente-se reduzido e degradado. Em geral, tentamos trazer a nossa "sombra" sob o controle e a dominação dos nossos egos. Admitir a existência da "sombra" providencia um completo senso de autoconhecimento, auto-aceitação e uma sensação se estar vivo. A ideia de "sombra" de Jung envolve força e passividade, beleza e horror, poder e impotência, força e fraqueza, sabedoria e infantilidade, sensatez e insensatez. A submissão à dor masoquista, a perda de controle e a humilhação servem para admitir a existência da nossa “sombra”, em vez de negá-la (JUNG, 1981).

As teorias psicológicas ajudam-nos a contextualizar esse fenômeno; porém, devido à falta de evidências mais concretas, não dão conta de explicá-lo.

\section{Contextualização nos Estudos do Gênero}

Os estudiosos e estudiosas do gênero por muito tempo mantiveram-se afastados das questões relativas ao sadomasoquismo, seja pela pouca visibilidade dessas práticas, seja pela ainda pouca produção teórica no mundo. No Brasil, pesquisas sobre violência na área do gênero só aparecem quando a problemática sobre a violência contra a mulher passou a existir como problema social a partir das lutas feministas no início dos anos 80 e com a posterior criação das delegacias da mulher (CORREA, 1981; CHAUÍ, 1985; AZEVEDO, 1985; ARDAILLON \& DEBERT, 1987; BESSE, 1989; GREGORI, 1992; PACHECO, 1995; FONSECA, 1995; GROSSI, 1998).

Grossi (1998) resume as contribuições acadêmicas sobre a violência contra a mulher no Brasil a partir de dois paradigmas básicos: o primeiro é que vivemos em uma sociedade com valores patriarcais, na qual os homens usam a sua violência para controlar e submeter as mulheres aos seus desígnios; o segundo é que não se pode isolar 
o pólo da mulher para entender a violência em uma relação afetivo/conjugal como uma via de mão única.

Autores que trabalham com o paradigma da violência masculina geralmente apóiam-se nos pressupostos teóricos de Bourdieu (1996) e Héritier (1989). Embora esse primeiro paradigma seja o mais difundido, a relativização dessa percepção mais monolítica começou a se desconstruir a partir das contribuições de Foucault (1985), Strathern (1988) e Correa (1999).

$\mathrm{Na}$ atualidade, Grossi (1998) salienta a necessidade de perceber a violência contra a mulher a partir da interação de cada casal, assim como a partir do contexto cultural no qual esse vínculo afetivo/conjugal está inserido. Assim, criou-se um ambiente propício para empreender nos estudos de gênero maiores esforços para entender o sadomasoquismo não mais como um fenômeno hediondo e repugnante, e sim como mais um aspecto do anthropos humano, operando nas relações de gênero como um todo. A dominação passa a não ter mais um gênero definido, apresentando um caráter transitório entre os pares envolvidos.

\section{Comportamento Sexual nas Práticas Sadomasoquistas}

As causas da excitação sexual ainda não são totalmente compreendidas, mas já existem certas evidências que justificam algumas especulações relacionadas ao sadomasoquismo. Muitas dessas especulações estão ligadas à idéia do nível de consciência de si próprio e do nível de prazer e excitação sexual. Alguns teóricos acreditam que um completo prazer sexual só pode ser experimentado quando os indivíduos conseguem deixar à parte sua própria autoconsciência, colocando-se como seres autônomos e independentes dos seus laços sociais. Por exemplo, de acordo com LoPiccolo (1978), o direcionamento do sexo enquanto mera performance ou conquista pode afastar as pessoas do real excitamento e da funcionalidade sexual - o processo.

O trabalho de Master e Johnson (1970) precede os estudos de psicologia social da autopercepção, mas os seus achados parecem envolver alguns aspectos desse conceito. As técnicas de terapia sexual propostas pelos autores em um dos mais conhecidos 
programas clínicos de sexualidade têm um importante paralelo com as atividades sadomasoquistas, como, por exemplo:

- há uma grande ênfase no isolamento social dos parceiros sexuais das demandas do diaa-dia;

- o que Master e Johnson chamam de "foco sensível” em seu programa envolve atenção direcionada para as sensações mais imediatas, o qual parece ser o mesmo foco das atividades sadomasoquistas;

- a terapia de Master e Johnson enfatiza o casal em relação ao indivíduo, semelhantemente ao que ocorre nas práticas sadomasoquistas;

- propõe-se o uso terapêutico da técnica da permissão pelo terapeuta que controla todo o processo, tal como nos jogos sadomasoquistas, em que também há similar permissão, comandos e restrições;

- o uso de técnicas nas quais o paciente com problemas de ejaculação precoce ou dificuldades de ereção deve submeter-se a comandos de outros, tal como nas práticas sadomasoquistas, em que se impõe a passividade ao dominado.

Considerando essas similaridades de técnicas, mesmo que em diferentes contextos, pode-se dizer que as práticas sadomasoquistas poderiam em princípio aumentar a excitação sexual, já que o masoquismo seria interessante para indivíduos que desejam melhorar a sua insegurança sexual e aumentar a intensidade de suas sensações e experiências. Além disso, os jogos sexuais sadomasoquistas geralmente duram mais do que as carícias típicas que precedem as práticas sexuais tradicionais e têm maior tempo de exposição da nudez e do contato corporal, o que permitiria condições mais favoráveis de se atingir maiores níveis de excitação sexual.

Alison e colaboradores (2001) estudaram 184 sujeitos (22 mulheres e 162 homens) membros de clubes sadomasoquistas através de um questionário semi-estruturado contendo vários itens relacionados a variedades de comportamentos sexuais. Usando uma análise estatística de multivariância, emergiram quatro diferentes cenários em termos qualitativos: hipermasculinidade, administração e recebimento de dor, restrições físicas e humilhação psicológica. Embora esses temas já tivessem sido sugeridos 
anteriormente, este foi o primeiro estudo científico que comprovou com bases empíricas tal caracterização da sexualidade sadomasoquista baseada na tradicional percepção unilinear do poder masculino dominante subjugando o feminino.

Em uma sessão sadomasoquista, o pré-requisito é a presença da dicotomia "dominante-dominado", que não está condicionada diretamente à orientação sexual ou ao sexo biológico do parceiro. Homens e mulheres, heterossexuais ou homossexuais podem assumir ambas as posições de dominante e dominado. No entanto, nas cenas homossexuais, geralmente o dominante também é o ativo ou o penetrador, uma vez que o dominado está impedido de tomar qualquer iniciativa.

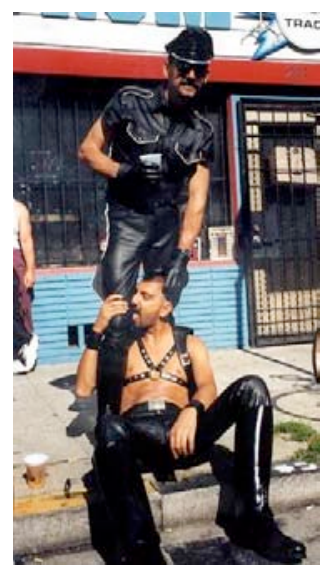

Foto 11: a relação dominante-

dominado entre homossexuais.

Contudo, até mesmo essas posições podem ser negociadas previamente. Por exemplo, se dois homossexuais supostamente dominantes têm interesses sexuais recíprocos, um deles pode abrir mão da sua posição de dominante com o objetivo de viabilizar o prazer de ambos (KAMEL, 1983).

Talvez a grande contribuição dos sadomasoquistas nas discussões sobre as relações de poder esteja na valorização, no exagero e na visibilidade da polarização entre dominante e dominado, mas assumem e dão visibilidade também à possibilidade de que 
essas posições sejam invertidas e negociadas com o objetivo de propiciar práticas sexuais mais prazerosas para ambos. Assim, os estereótipos de dominante/dominado e masculino/feminino são fundamentais na contextualização das práticas sadomasoquistas, porém as decisões e as negociações interpessoais são a força motriz de todo esse processo - a ritualização controlada, acordada e concedida da violência. No cotidiano, tal violência adquire um caráter descontrolado de oprimir, degradar e até mesmo matar. Desse modo, o dito popular "Quem ama não mata" só faz sentido para os sadomasoquistas.

Em geral, os sadomasoquistas heterossexuais e homossexuais estão socialmente organizados em distintos guetos que acomodam as suas respectivas necessidades de parceiros e prazer sexual. Os homossexuais sadomasoquistas, via de regra, têm mais opções sociais, devido à crescente organização social gay que comumente é menos preconceituosa com relação a tais práticas e seus praticantes (KAMEL, 1983).

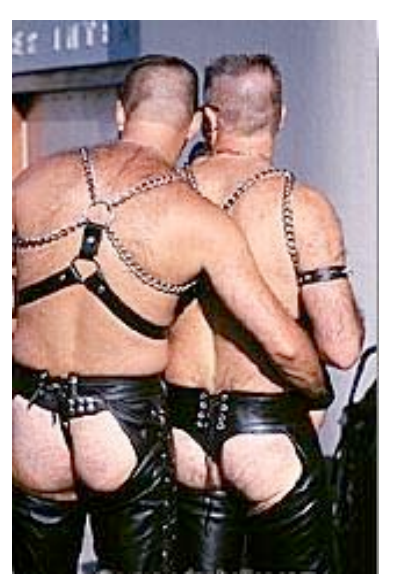

Foto 12:

sadomasoquismo homossexual. 
Apesar de os sadomasoquistas serem uma minoria nas comunidades gays, sempre existe um bar, uma danceteria, uma sauna ou um clube de sexo que reserve e promova um dia da semana especialmente para esse grupo nas grandes cidades pelo mundo afora. Segundo Weinberg e Falk (1983), os heterossexuais têm bem menos possibilidades de acesso a esses lugares, tendo que se restringir a anúncios em revistas especializadas, a prostitutas especializadas ou a encontros casuais. Com exceção de poucas cidades no mundo, como São Francisco, Nova York e Amsterdã, quase não existem ambientes públicos como bares ou clubes de sexo especializados para os sadomasoquistas heterossexuais. Breslow (2003) encontrou uma grande diferença em relação à freqüência a bares e clubes de sexo sadomasoquistas entre heterossexuais e homossexuais: $8 \%$ dos heterossexuais e $42 \%$ dos homossexuais afirmaram frequentar esses locais. Mais uma evidência de que não existem muitas opções para os heterossexuais.

\section{Homens, Mulheres, Homossexuais, Lésbicas}

Sandnabba, Santtila e Nordling (1999) estudaram um total de 164 homens, metade homossexuais e metade heterossexuais, através de um questionário semi-estruturado contendendo aspectos sociais, sexuais e psicológicos em membros de dois clubes com orientações sadomasoquistas na Finlândia. Os resultados mostraram que esses praticantes de sadomasoquismo são socialmente bem ajustados e que tal comportamento é apenas um aspecto facilitador de suas vidas sexuais, sendo que a maioria dos

participantes mostrou-se flexível em relação aos papéis de dominante e submissivo. Entretanto, os sadistas eram mais jovens e mais ativos sexualmente do que os masoquistas.

Baumeister (1988), através de análises estatísticas de cartas anônimas enviadas para revistas com orientação sadomasoquistas, estudou as diferenças de gênero em relação ao papel masoquista. Os resultados mostram que os homens masoquistas excedem as mulheres nos quesitos como severidade da dor, humilhação em grupo, humilhação de baixo status, humilhação oral, infidelidade assistida do parceiro, participação ativa de uma terceira pessoa e travestismo. 
O comportamento masoquista das mulheres supera o dos homens apenas em relação à frequência da dor, em punição com dor contextualizada a erros cometidos nas relações afetivas, em humilhação envolvendo exposição exibicionista, em intercurso genital com o parceiro e na não participação de espectadores. Segundo o autor, essas diferenças podem ser interpretadas como influência dos estereótipos sociais do que sejam comportamentos masculinos e femininos (BAUMEISTER, 1988). Tais estereótipos tornam-se pano de fundo, dando maior significado às condições e às representações binomiais de dominante e dominado.

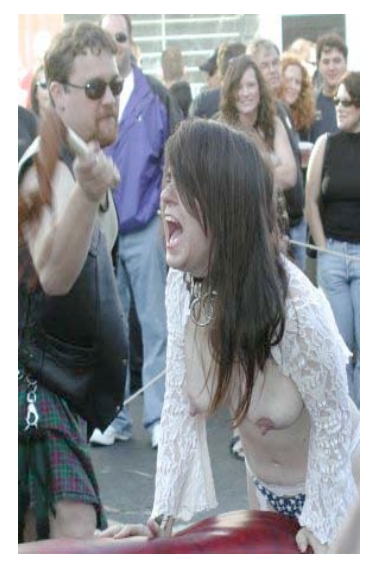

Foto 13: mulher submissiva em uma sessão de relho.

Alison e colaboradores (2001) relatam que a humilhação foi significativamente associada mais às mulheres e aos homens com inclinações heterossexuais, enquanto a hipermasculinidade estava associada aos homens em geral e aos homens com inclinações homossexuais.

A existência de mulheres na subcultura sadomasoquista tem sido geralmente desconsiderada em termos teóricos, clínicos e empíricos na literatura vigente. Breslow, Evans e Langley (1985) foram os primeiros a estudar a prevalência e os papéis das mulheres nesse grupo. Através de duas publicações sadomasoquistas, além de questionários enviados a pontos de encontro de sadomasoquistas, os autores tiveram 182 respondidos, 130 homens e 52 mulheres, indicando uma presença significativa destas.

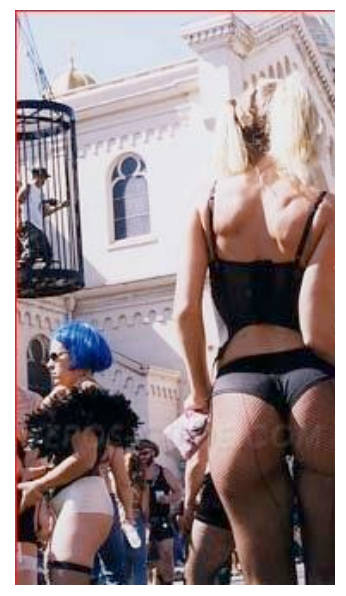

Foto 14: Folson

Fair Street/2001

(Cardoso, 2001). 
Mais tarde, Levitt Moser e Jamison (1994) estudaram a prevalência e alguns atributos das mulheres na subcultura sadomasoquista. Considerando que mulheres nãoprostitutas associadas ao sadomasoquismo são mais raras de serem encontradas, a referida pesquisa selecionou uma amostra de 45 mulheres sadomasoquistas, sendo que destas 34 não são prostitutas. Os autores concluíram que essas mulheres tornaram-se conscientes de suas inclinações eróticas ainda quando jovens e estão satisfeitas com tal condição.

Essas mulheres tendem a apresentar melhor nível de instrução e menor probabilidade de serem casadas. A maioria delas autodefiniu-se como heterossexuais, mas existe uma minoria de bissexuais. Elas tendem a preferir o papel submissivo, mas muitas também estão abertas para ambos os papéis ou até mesmo o papel de dominadora. As práticas favoritas são sexo oral e bandagem (LEVITT, MOSER \& JAMISON, 1994). Breslow (2003) também constatou preferências sexuais similares por parte das mulheres, mas incluiu o espancamento como uma outra atividade também popular entre elas.

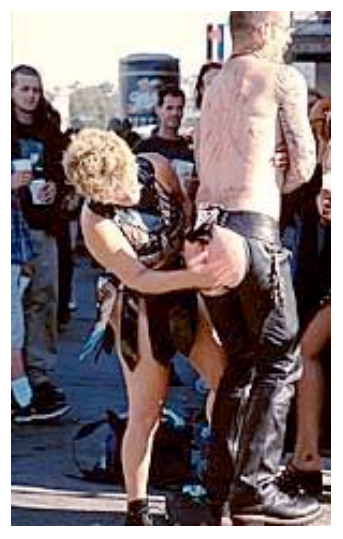

Foto 15: mulher dominante em uma interação heterossexual (Cardoso, 2001).

A maior contribuição científica sobre as questões relativas ao sadomasoquismo aparece somente a partir de 1999 com Norman Breslow. A autora analisou questionários enviados a todos os 50 estados norte-americanos, assim como ao Canadá, à Europa e à América do Sul, sendo que retornaram 855 questionários preenchidos por homens e 176 questionários preenchidos por mulheres. Entre as mulheres respondentes, 43 alegaram ser profissionais do sexo e 5 abstiveram-se de responder a essa pergunta. Em suma, 1 mulher para cada 5 homens fez parte dessa amostragem. Apesar de não ser uma pesquisa probabilística, algo quase impossível nessa área, a autora conseguiu ao longo de anos de pesquisa no assunto reunir uma das maiores amostragens até agora analisadas. 
Breslow (2003) resumiu a análise de seus dados da seguinte forma: 1) quase todos os participantes são brancos; 2) diferentemente dos resultados de muitos autores (JANUS, BESS E SALTUS, 1977; SPENGLER, 1977; SCOTT, 1983), os participantes ocupam posições sociais extremamente variadas, desde executivos até operários e assistentes de serviços em geral, da classe popular, o que desmistificaria a preponderância de uma elite como praticantes de sadomasoquismo; 3) os respondentes têm bom nível de instrução (63\% dos homens e 40\% das mulheres afirmaram ter curso superior ou pós-graduação); 4) entre os respondentes, existe um número significativamente maior de bissexuais entre as mulheres do que entre os homens; 5) em geral, os homens descobrem a sua orientação sadomasoquista um pouco mais cedo do que as mulheres; 6) cerca de $54 \%$ das mulheres e apenas $8 \%$ dos homens foram introduzidos a essa prática por intermédio de seus parceiros sexuais, ao passo que $16 \%$ dos homens e 4\% das mulheres afirmaram tê-la descoberto através do manuseio de pornografia; 7) cerca de $62 \%$ dos homens e $52 \%$ das mulheres alegaram que as práticas sadomasoquistas facilitam o orgasmo, enquanto apenas 9\% dos homens e 17\% das mulheres alegaram que o sadomasoquismo não têm influências sobre o seu orgasmo; 8) com relação aos papéis sexuais nas cenas sadomasoquistas, 30\% dos homens e 32\% das mulheres assumiram-se dominantes, $44 \%$ dos homens e $38 \%$ das mulheres assumiram-se versáteis e $26 \%$ dos homens e $33 \%$ das mulheres assumiram-se submissivos; 9) os homossexuais têm muito mais parceiros sexuais do que os heterossexuais e as mulheres bissexuais têm mais sessões com mais parceiros do que as heterossexuais.

Com o objetivo de testar uma possível relação entre o nível de desejo de exercer controle sobre o destino de suas vidas e os papéis sexuais assumidos nas cenas sadomasoquistas, Breslow (1987) utilizou uma escala sobre o "desejo de controle" (Desirability of Control Scale). Ainda que todos os integrantes tenham demonstrado um alto desejo de obter controle sobre si mesmos, independentemente de suas preferências por papéis sexuais nas práticas sadomasoquistas, a escala classificou os respondentes em três grupos básicos. Disso decorreram diferenças estatisticamente significativas: os dominantes têm um maior desejo de controle do que os versáteis, e os versáteis têm um maior desejo de controle do que os submissivos. Esses dados evidenciam que existem 
três tipos básicos de papéis sexuais nas cenas sadomasoquistas, e não apenas um grande grupo de versáteis como se supunha anteriormente.

\section{Considerações Finais}

As primeiras evidências das práticas sadomasoquistas advêm do século XVIII, período da Revolução Industrial, em que se estrutura o conceito de indivíduo e os moldes da burguesia. Mesmo reconhecido como um fenômeno social já no século XVIII, são poucas as tentativas científicas de entender o mundo sadomasoquista. Estamos muito distantes de ter uma percepção média típica do que são, de como se comportam e do que diferencia os adeptos dessa prática, se é que existem tais diferenças. Talvez melhor do que tentar produzir apenas uma descrição densa do sadomasoquismo seja testar cientificamente os tradicionais mitos e opiniões sobre essas práticas.

Alguns mitos - como o de que as mulheres não têm interesse por essas práticas, ou que a pornografia desperta interesses eróticos desse tipo, ou que os sadomasoquistas são parafilicos, ou ainda que os homens são dominantes e as mulheres submissivas - não se sustentam mais como um fato, pois muitas vezes negociamos ou nos sujeitamos às regras do jogo, mesmo que de forma não percebida, esperando por premiações ou recompensas afetivamente gratificantes.

A minha convivência, como sexólogo, com a comunidade e as organizações civis sadomasoquistas em São Francisco ensinou-me que essas práticas são representações cênicas exageradas de sentimentos cotidianos presentes em qualquer relação pessoal ou social. Os sadomasoquistas não têm vergonha de assumir que a dor, seja ela qual for, também tem uma função afrodisíaca, significativa e acolhedora quando dissolve de forma controlada as fronteiras do "self". Esse fato sustenta as inferências tão polêmicas de Gregori (1992) e Grossi (1998) de que a violência doméstica pode assumir diferentes representações sociais. Por exemplo, a opressão e a subjugação da mulher por meio da agressão física ou simbólica de seus companheiros ou, em alguns casos, a violência como algo prazeroso e compensador em algumas situações conjugais de conflito. $\mathrm{Na}$ vida real, porém, em que as regras não estão claras e não existe a "palavra de segurança" que é 
utilizada pelo masoquista para sinalizar o seu limite, a violência pode tomar caminhos indesejados.

Para concluir, sugere-se que a comunidade científica e clínica reveja os seus conceitos de natureza patológica sobre as práticas sadomasoquistas, passando a considerá-las também como um veículo saudável para relaxar os nossos mecanismos de defesa com o objetivo de neutralizar a nossa constante ânsia de controle sobre pessoas e situações. Quando se atinge essa liberdade sobre o dever de sempre ter controle sobre tudo, passa-se também a cultivar e promover essas novas formas de se explorar, conhecer e aceitar as porções mais sombrias da nossa personalidade humana.

\section{Referências Bibliográficas}

ALISON, L., SANTTILA, P., SANDNABBA, K., \& NORDLING, N. (2001).

Sadomasochistically oriented behavior: Diversity in practice and meaning. Archives of Sexual Behavior, 30 (1), 1-12.

ARDAILLON, D. \& DEBERT, G. (1987). Quando a vítima é mulher: Análise de julgamentos de crimes de estupro, espancamento e homicídio. Brasília: Conselho Nacional dos Direitos da Mulher.

AZEVEDO, M. A. (1985). Mulheres espancadas: A violência denunciada. São Paulo: Editora Cortez.

BAUMEISTER, R. (1988). Masochism as escape from self. Archives of Sexual Behavior, 25(1), 28-59.

BAUMEISTER, R. (1988). Gender differences in masochistic scripts. Archives of Sexual Behavior; 25 (4), 478-499.

BENJAMIN, H. \& MASTERS, R. E. L. (1965). Prostitution and morality. London: Souvenir Press.

BESSE, S. 1989. Crimes passionais: A campanha contra assassinos de mulheres no Brasil: 1910/1940. Revista Brasileira de História; 1.9(18), 181-198.

BOURDIEU, P. (1996). Razões e práticas: Sobre a teoria da ação. São Paulo: Papirus.

BRESLOW, N. (2003). Norman Breslow's Achieves. Acessado em 01 de junho de 2003. Disponível em: <http://www.sexuality.org/l/nb/nbres.html>

BRESLOW, N. (1987). Locus of control, desirability of control, and sadomasochisms. Psychological Reports, 61, 995-1001.

BRESLOW, N., EVANS, L., \& LANGLEY, J. (1985). On the prevalence and roles of females in the sadomasochistic subculture: Report of an empirical study. $r$, 14(4), 303-317.

BULLOUGH, V. (1976). Sexual variance in society and history. Chicago (IL): University of Chicago Press.

CALIFIA, P. (1983). A secret side of lesbian sexuality. IN: WEINBERG T. \& KAMEL L. (orgs.), $\mathbf{S}$ and M: Studies in Sadomasochism (pp.129-136). Buffalo: Prometheus.

CHAUÍ, M. (1985). Participando do debate sobre mulher e violência. Perspectivas Antropológicas da Mulher, n.4. Rio de Janeiro: Editora Zahar. 
CORREA, M. (1981). Os crimes da paixão. São Paulo: Editora Brasiliense.

CORREA, M. (1999). O sexo da dominação. São Paulo: Novos Estudos (CEBRAP).

DIAGNOSTIC AND STATISTICAL MANUAL OF MENTAL DISORDERS, $4^{\text {th }}$ edition. (1994). American Psychiatric Association. Acessado em 10 de junho de 2003. Disponível em:

$<$ http://www.behavenet.com/capsules/disorders/sexmasochism.htm> $<$ http://www.behavenet.com/capsules/disorders/sexsadismTR.htm>

FONSECA, C. (1995). A mulher valente: Gêneros e narrativas. Horizontes Antropológicos, n. 1: gênero. Porto Alegre: PPGAS/UFRGS.

FOUCAULT, M. (1985). História da sexualidade. Rio de janeiro: Graal.

FRANKLIN, D. (1987). The politics of masochism. Psychology Today, 21(1), 52-56.

FREUD, S. (1983). Sadism and masochism: Basic writing of Sigmund Freund. New York: Modern Library; 1938. Reprint in Weinberg, T. \& Kamel, L. (orgs.). $\mathrm{S}$ and $\mathrm{M}$ (pp30-32). Bufallo: Prometheus.

FREUD, S. (1953). Three Essays on the Theory of Sexuality. Em Strachey, J. (org.), The Complete Psychological Works of Freund. London: Holgarth.

FRIDAY, N. (1980). Men in Love. New York: Dell.

GREGORI, M. F. (1992). Cenas e queixas - Um estudo sobre mulheres, relações violentas e a prática feminista. Rio de Janeiro: Paz e Terra/ANPOCS.

GROSSI, M. (1998). Rimando amor e dor: Reflexões sobre a violência no vínculo afetivoconjugal. IN: JOANA, P.\& GROSSI, M. (orgs.), Masculino, feminino, plural: Gênero na interdisciplinaridade (pp. 293-313). Florianópolis: Editora Mulheres.

HÉRITIER, F. (1989). Incesto. Enciclopédia Einaudi - Parentesco, volume 20. Lisboa: Imprensa Nacional.

HAYDEN, D. (2003). Psychological dimensions of masochistic surrender. Acesso em 10 de junho de 2003. Disponível em: $<$ http://www.sextreatment.com/psych.htm>

HULL, J., \& YOUNG, R. (1983). Self-consciousness, self-esteem, and success-failure as determinants of alcohol consumption in male social drinkers. Journal of Personality and Social Psychology, 44 (6), 1097-1109.

HULL, J. \& YOUNG, R. (1981). A self-awareness model of the causes and effects of alcohol consumption. Journal of Abnormal Psychology, 90, 586-600.

HULL, J., YOUNG, R., \& JOURILES, E. (1986). Application of the self-awareness model of alcohol consumption: Predicting patterns of use and abuse. Journal of Personality and Social Psychology, 51(4): 790-796.

JANUS, S., BESS, B., \& SALTUS, C. (1977). A Sexual Profile of Men in Power. Englewood Cliffs: Prentice-Hall.

JUNG, C. (1964). Man and His Symbols. New York: Doubleday and Company Inc. JUNG, E. (1981). Animus and Anima. Dallas: Spring Publication.

KAMEL, L. (1983). The leather carrier: On becoming a sadomasochist. In:

WEINBERG, T., \& KAMEL, L. (orgs.), $S$ and $M$ : Studies in Sadomasochism (pp. 73-79). Buffalo: Prometheus.

LEE, J. A. (1983). The social organization of sexual risk . In: WEINBERG, T., \& KAMEL, L. (orgs.), S and M: Studies in Sadomasochism (pp.175-196). Buffalo: Prometheus. 
LEVITT, E., MOSER, C., \& JAMISON, K. (1994). The prevalence and some attributes of females in the sadomasochism subculture: A second report. Archives of Sexual Behavior, 23(4), 465-473.

LEWIN, K. K. (1980). Sexuals Self-destruct: Conscience of the West. Saint Louis: Green.

LIEBLING, B. A., SEILER, M., \& SHAVER, P. (1974). Self-awareness and cigarette smoking behavior. Journal of Experimental Social Psychology, 10, 325332.

LOPICCOLO, J. (1978). Direct treatment of sexual dysfunction. In: LOPICCOLO, J. \& LOPICCOLO, L. (orgs.), Handbook of sex therapy (pp.1-18). New York: Plenum.

MASTER, W. \& JOHNSON, V. (1970). Human sexual inadequacy. Boston: Little, Brown \& Co.

MONEY, J. (1998). Gay, straight, and in-between: The sexology of erotic orientation. New York: Oxford University Press.

PACHECO, C. (1995). A violência à mulher: Uma análise sócio-criminal. Relatório Final de Pesquisa - Departamento de Apoio a Pesquisa/CNPq, Florianópolis (SC), UFSC.

REIK, T. (1941). Masochism in Modern Man. New York: Grove Press.

SAMOIS. (1982). Coming to power. Boston: Alyson.

SANDNABBA, K., SANTTILA, P., \& NORDLING, N. (1999). Sexual behavior and social adaptation among sadomasochistically-oriented males. The Journal of Sexual Research, 36(3), 273-282.

SCOTT, G. (1983). Erotic power: An exploration of dominance and submission.

Secaucus: Citadel Press.

SHAINESS, N. (1984). Sweet suffering: Woman as victim. New York: Simon \& Schuster.

SIMANSKI, R. (1981). The immoral landscape: Female prostitution in Western societies. Toronto: Butterworth \& Co.

SPENGLER, A. (1997). Manifest sadomasochism of males: Results from an empirical study. Achieves of Sexual Behavior, 6, 441-456.

STEKEL, W. (1953). Sadism and masochism: The psychology of hatred and cruelty (trad. Gutheil E.). New York: Liveright.

STRATHERN, M. (1988). The gender of the gift: Problems with women and problems with society in Melanesia. Berkeley: University of California Press.

TANNAHILL, R. (1980). Sex in History. New York: Stein and Day.

TAYLOR, R. (1970). Sex in History. New York: Harper \& Row.

WEINBERG, T.\& KAMEL, L. (1983). S and M: Studies in sadomasochism. Buffalo: Prometheus.

WEINBERG, T. \& FALK, G. (1983). The social organization of sadism and masochism. In: WEINBERG, T. \& KAMEL, L. (orgs.), $\mathrm{S}$ and $\mathrm{M}$ : Studies in Sadomasochism (pp.149-161). Buffalo: Prometheus.

WICKLUND, R. (1975). Discrepancy reduction or attempted distraction? A reply to Liebling, Seiler \& Shaver. Journal of Experimental Social Psychology, 11, 78-81. 